\title{
Inorganic and Organic Acids in the Atmosphere of the Urban Area of the City of Salvador, Brazil
}

\author{
Lícia P. S. Cruz, ${ }^{\circ *, a}$ Elisvan R. Mota, ${ }^{a}$ Vânia P. Campos, ${ }^{a}$ Franciele O. Santana, ${ }^{a}$ \\ Sâmeque R. Luz ${ }^{a}$ and Daniela F. Santos ${ }^{a}$ \\ ${ }^{a}$ Departamento de Química Analítica, Instituto de Química, Universidade Federal da Bahia, \\ 40170-115 Salvador-BA, Brazil
}

\begin{abstract}
Different fuels are used in Brazil and there is little knowledge about the presence of organic and inorganic acids in the atmosphere of the Brazilian cities. $\mathrm{HNO}_{3}, \mathrm{HCl}, \mathrm{HCOOH}$ and $\mathrm{CH}_{3} \mathrm{COOH}$ were sampled in the gas phase using passive samplers and thermodiffusion system, in which the $\mathrm{H}_{2} \mathrm{SO}_{4}$ particulate was also sampled, in five sites of Salvador. Ion chromatography analyses showed that the organic and inorganic acids measured contributed on average with 89 and $11 \%$, respectively, to the acidity of the city's atmosphere. The strong correlations between $\mathrm{HCOOH}, \mathrm{CH}_{3} \mathrm{COOH}$ and $\mathrm{HCl}$ with $\mathrm{CO}$ and $\mathrm{NO}_{2}$ indicated a common source for these compounds, predominantly from vehicular emissions. $\mathrm{H}_{2} \mathrm{SO}_{4}$ showed strong correlations with $\mathrm{PM}_{10}$ (particulate matter $10 \mu \mathrm{m}$ or less in diameter) and with its precursor $\mathrm{SO}_{2}$; and $\mathrm{HNO}_{3}$ with $\mathrm{NO}_{2}$ and $\mathrm{NO}$ precursors. Most of the compounds presented negative correlations with meteorological parameters. Principal component analysis (PCA) and hierarchical cluster analysis (HCA) confirmed these observations. The ratios $[\mathrm{HCOOH}] /\left[\mathrm{CH}_{3} \mathrm{COOH}\right]$ varied between 0.69-1.9, typical of urban areas.
\end{abstract}

Keywords: formic acid, acetic acid, hydrochloric acid, nitric acid, particulate sulfuric acid, urban atmosphere

\section{Introduction}

Air pollution has been considered the main environmental degradation agent of the planet. The major air pollution problems arise from the release of gases and particles into the atmosphere, and the main sources are vehicles and industrial activities. The magnitude of the impact on air quality depends on the prevailing weather conditions, which is responsible for the transportation, transformation and dispersion of the emitted pollutants, as well as the possible occurrence of critical situations of air pollution. The action of pollutants is further aggravated when weather conditions are unfavorable to their dispersion in the atmosphere. ${ }^{1,2}$

One of the most subtle problems related to the air quality degradation is the presence of acids in the atmosphere, which can be transported and deposited by dry or wet processes, mainly by rain, producing one of the most well-known phenomena in terms of atmospheric pollution: acid rain. Until recently, the studies only considered the inorganic acids (sulfuric, nitric and hydrochloric acids) and their precursors (sulfur dioxide and nitrogen oxides)

*e-mail: lila@ufba.br as the main cause for atmospheric acidity. In contrast, organic acids, mainly formic and acetic, have been poorly investigated. Nevertheless, it is estimated that 16 to $35 \%$ of the free acidity in rainwater in urban environments and $65 \%$ in remote areas are due to the presence of these compounds. $^{3}$

Formic and acetic acids are the most abundant low molecular weight carboxylic acids in the global troposphere. They can either be emitted by direct sources such as vehicular exhaust emissions, biomass burning, biofuel, fossil fuel and vegetation, or be formed in the atmosphere by photochemical reactions. These acids are considered ubiquitous components in the troposphere and are found in aqueous and gaseous phases, as well as in atmospheric particles. ${ }^{4}$

In the atmosphere, the gas-gas interactions (called homogeneous reactions in the gas phase), the reactions occurring in aqueous phase with or without the presence of catalysts, as well as the reactions on solid surfaces, may all be responsible for the oxidation of sulfur dioxide into sulfuric acid and sulfate salts. The latter are more stable in the troposphere, thus they are more susceptible to be incorporated into solid or liquid aerosol particles, 
being easily removed from the atmosphere by physical processes of wet and dry deposition, contributing to the acidification of the precipitation. Also, they can act as cloud condensation nuclei with possible climatic consequences. ${ }^{2}$

The reaction between the hydroxyl radical $(\mathrm{HO} \bullet)$ and nitrogen dioxide $\left(\mathrm{NO}_{2}\right)$ is the main process of $\mathrm{NOx}$ $\left(=\mathrm{NO}+\mathrm{NO}_{2}\right)$ loss during the day and it is important for the formation of nitric acid $\left(\mathrm{HNO}_{3}\right)$ in urban areas with high concentrations of $\mathrm{NO}_{2}$. This reaction is fast enough to form significant amounts of $\mathrm{HNO}_{3}$ during the day, especially in polluted areas. The formation and subsequent hydrolysis of dinitrogen pentoxide $\left(\mathrm{N}_{2} \mathrm{O}_{5}\right)$ on moist surfaces, including aerosols, also gives a significant contribution to the formation of $\mathrm{HNO}_{3}$ in the atmosphere at night in both local and global scales. ${ }^{2,5}$

Hydrochloric acid $(\mathrm{HCl})$ is produced mainly by the incineration of industrial waste and the burning of coal and fossil fuels containing chlorine. It may also be generated naturally through atmosphere reactions of other acids such as sulfuric and nitric acids with the sodium chloride $(\mathrm{NaCl})$ of the marine aerosol. ${ }^{6}$

Since the late 1980s in Brazil, regulations on vehicle emissions have been adopted through the Vehicle Air Pollution Control Program (PROCONVE) ${ }^{7}$ and there have been improvements in fuel quality. However, the increase in the vehicle fleet in circulation due to the low-quality public transportation systems in the great urban centers has intensified the traffic in these places, resulting in environmental degradation, mainly caused by air pollution. The Brazilian fuel matrix is different from other countries in the world due to the use of various fuels, including compressed natural gas (CNG), diesel with $10 \%$ biodiesel, hydrated ethanol and a mix of gasoline with $25-27 \%$ of anhydrous ethyl alcohol, which is called gasohol. ${ }^{8,9}$

Organic acids can be emitted to the atmosphere as a consequence of the incomplete combustion of fuels as well as by the use of additives in vehicles. Moreover, these, and also inorganic acids, can be formed by reactions in the atmosphere, contributing to the degradation of air quality. However, in Brazilian states, there is little knowledge about the presence of inorganic and organic acids. It was only in the state of São Paulo that some studies were carried out aiming to determine the concentrations of organic acids in the atmosphere. ${ }^{10-12}$ In the state of Bahia, some studies were carried out by a group of the Laboratory of Environmental Analytical Chemistry (LAQUAM) of the University Federal of Bahia (UFBA) in some municipalities of the Recôncavo Baiano, to evaluate the spatial distribution of inorganic acids (nitric, hydrochloric and sulfuric) in the atmosphere of this region, in the rainy and dry periods of 1994, 1995, 2008 and 2010. ${ }^{13,14}$
In atmospheric monitoring, the determination of pollutant concentrations can be performed by two types of sampling methods: active and passive. In the active sampling, the air is sucked into the sampling device with the aid of a vacuum pump, measuring the air volume or sampling rate. Passive sampling is based on physical processes, such as diffusion and permeation, without involving the forced movement of the air through the sampler. The application of passive samplers, when compared to the active techniques, has the advantages of: being simple, low cost, small and portable; allowing simultaneous sampling in wide areas; not requiring electricity nor measurements of the volume of air sampled; and giving the results in the form of time-weighted average concentration. These characteristics make these samplers suitable for air monitoring applications in indoor and outdoor environments, including urban areas. ${ }^{13,15,16}$

It is possible to collect strong inorganic $\left(\mathrm{HCl}\right.$ and $\left.\mathrm{HNO}_{3}\right)$ and organic acids (formic and acetic) using the passive sampling because they are all gases. However, sulfuric acid $\left(\mathrm{H}_{2} \mathrm{SO}_{4}\right)$, which is present in the atmosphere in the particulate phase $(<2 \mu \mathrm{m})$, is only suitably sampled by active methods based, for example, on thermodiffusion., ${ }^{2,13}$

In Salvador, with about 3 million inhabitants and a fleet of more than 800,000 vehicles, no study has been carried out previously to assess the levels of acids in the atmosphere of the city. Thus, this study aimed to determine the concentrations of strong inorganic acids and low molecular weight organic acids present in the atmosphere of the city of Salvador, Brazil, and evaluate the correlations between the studied acids, criteria air pollutants and meteorological parameters, as well as the relationships among the sampling sites.

\section{Experimental}

\section{Sampling}

\section{Description of the study area: Salvador-BA, Brazil}

Salvador, the capital of the state of Bahia, located in the northeast coast of Brazil (12 $58^{\prime} 16^{\prime \prime} \mathrm{S}$ and 38 $30^{\prime} 39^{\prime \prime} \mathrm{W}$ ), has a humid tropical climate, high relative humidity, and an annual average temperature of around $25^{\circ} \mathrm{C}$. The lowaltitudes topographical distribution, associated with small thermal variations, allows the penetration of trade winds (northeast, southeast and east) to the interior of the city, which favors a good dispersion of atmospheric pollutants. The city receives little influence of industrial emissions, being an urban area that is impacted mainly by vehicular emissions.

The samplings were carried out in five sites during two different periods of 2014, May/July (rainy season) and 
November/December (dry season), to evaluate the seasonal effects on the concentration distribution of the studied compounds. They are, in descending order of vehicular flow (number of vehicles per day): (A) Paralela, (B) Rio Vermelho, (C) Barros Reis, (D) Pirajá and (E) Campo Grande (Figure S1, Supplementary Information (SI) section). The five sites are potentially impacted by vehicular emissions. However, the sites $C$ and D have intense flow of heavy vehicles and the sites $\mathrm{B}$ and $\mathrm{E}$ have intense traffic of public transportation (buses). Site A has intense flow of light vehicles with vehicular flow (295,446 vehicles per day) 7 and 26 times greater than sites $\mathrm{B}$ and $\mathrm{E}$, respectively. ${ }^{16,17}$

\section{Description of the passive sampler}

The passive sampler used in this study for the sampling of $\mathrm{HNO}_{3}, \mathrm{HCl}$, formic acid $(\mathrm{HCOOH})$ and acetic acid $\left(\mathrm{CH}_{3} \mathrm{COOH}\right)$ (Figure 1) consists of a cylindrical body made of polyethylene $(12 \mathrm{~mm}$ length and $21 \mathrm{~mm}$ internal diameter) sealed at the bottom, containing a Teflon membrane (Millipore, polytetrafluoroethylene (PTFE), $0.5 \mu \mathrm{m}$ pore and $25 \mathrm{~mm}$ diameter) in the air inlet to minimize the particulate matter interference, and a stainless steel mesh (thread diameter $0.08 \mathrm{~mm}$ and mesh size $0.125 \mathrm{~mm}$ ) to minimize air turbulence effects and for membrane protection. After the diffusion layer, there is a cellulose filter impregnated with reagent specific to fixate the diffused gas through the sampler. ${ }^{18,19}$



Figure 1. Passive sampler and thermodiffusion system used in this study.

In the preparation of passive samplers for exposure, cellulose filters, that were previously washed three times with deionized water in ultrasonic bath, were immersed in the impregnation solution, then in water, as well as in ethanol for $15 \mathrm{~min}$ each, and then dried in an oven at $50{ }^{\circ} \mathrm{C}$.

All parts of the samplers and polyethylene containers (100 mL capacity) used for transport and storage were also washed with $2 \%$ neutral Extran, rinsed with deionized water, immersed in ethanol for $15 \mathrm{~min}$ and then dried. For the impregnating of the filters, aliquots of $200 \mu \mathrm{L}$ of the absorbing solution $\left(0.7 \mathrm{~mol} \mathrm{~L}^{-1}\right.$ triethanolamine $+1.0 \mathrm{~mol} \mathrm{~L}^{-1}$ glycerol) were added with a micropipette. The filters were dried in a desiccator containing silica gel for $48 \mathrm{~h}$. The samplers were then mounted, sealed with a flexible film to prevent contamination and placed in small polyethylene containers, stored in plastic bags, and finally sent to sampling.

The passive samplers were exposed for two week periods in 5 different sites of the city of Salvador, fixed to a support plate at a minimum height of $2 \mathrm{~m}$ and at least $1 \mathrm{~m}$ away from buildings, trees or other obstructions. After the exposure period, the samplers were sealed, taken to the laboratory and subsequently analyzed. The definition of which distribution passive samplers to use to characterize the atmosphere of the city of Salvador was determined by factors such as vehicle fleet, local safety and proximity to the air quality monitoring network stations.

To determine whether there was contamination during preparation, transport or analysis, two samplers of each type were used as field blanks, fully sealed, following the same trajectory of the exposed passive samplers, i.e., they were transported to the sampling sites, returning to the lab after the sampling period, without exposure.

\section{Description of the thermodiffusion system}

The thermodiffusion system (Figure 1) is composed of a virtual impactor at the entrance, two diffusion tubes of $90 \mathrm{~cm} \times 6 \mathrm{~mm}$ each, coated with $1.0 \times 10^{-2} \mathrm{~mol} \mathrm{~L}^{-1}$ sodium carbonate $\left(\mathrm{Na}_{2} \mathrm{CO}_{3}\right)$ connected in series, with a $30 \mathrm{~cm}$ diffusion tube also coated with sodium carbonate as trap for some sulfur compounds, and a filter holder to collect the fine particles in a membrane. A heating system maintained the temperature of the second diffusion tube at $140{ }^{\circ} \mathrm{C}$, where $\mathrm{H}_{2} \mathrm{SO}_{4}$ was sampled. With a flow rate of $138 \mathrm{~L} \mathrm{~h}^{-1}$, the air is introduced in the system, and the particles with aerodynamic diameter greater than $2.5 \mu \mathrm{m}$ are separated by the Teflon virtual impactor $\left(18 \mathrm{~L} \mathrm{~h}^{-1}\right)$ and collected in a $37 \mathrm{~mm}$ nuclepore filter with $0.2 \mu \mathrm{m}$ pore size. As significant losses can occur in this impactor, this filter is discarded. The air containing gaseous species and particles below $2.5 \mu \mathrm{m}$ is introduced in the diffusion tubes with a flow rate of $120 \mathrm{~L} \mathrm{~h}^{-1}$. Formic, acetic, nitric and hydrochloric acids were fixed on the walls of the first diffusion tube. The sulfuric acid droplets $(<2.0 \mu \mathrm{m})$, thermally unstable, were collected on the wall of the heated tube. At the end of the air stream, a membrane filter collected the fine particles, the thermically stable nitrogen compounds. ${ }^{13}$

\section{Analyses and quality control}

After the exposure of the passive samplers, the analytes fixed in impregnated filters were extracted with 
$1.5 \mathrm{~mL}$ of deionized water in unheated ultrasonic bath, followed by centrifugation for $5 \mathrm{~min}$ in microcentrifuge at $13,500 \mathrm{rpm}$. The anions of the acids were determined by ion chromatography with conductivity detection. The operating conditions used for determination of the organic and inorganic acids, respectively, were: anion separation column Dionex IonPac AS11 $(250 \times 4.0 \mathrm{~mm})$, eluent $\mathrm{Na}_{2} \mathrm{~B}_{4} \mathrm{O}_{7} \cdot 10 \mathrm{H}_{2} \mathrm{O}, 2.5 \mathrm{mmol} \mathrm{L}^{-1}$, flow $0.6 \mathrm{~mL} \mathrm{~min}^{-1}$; and anion separation column Dionex IonPac AS14 $(250 \times 4.0 \mathrm{~mm})$, eluent $3.0 \mathrm{mmol} \mathrm{L}^{-1} \mathrm{Na}_{2} \mathrm{CO}_{3} / 0.5 \mathrm{mmol} \mathrm{L}^{-1} \mathrm{NaHCO}_{3}$, flow

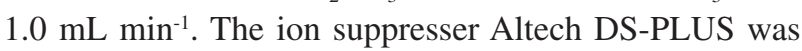
used in both cases. The analysis was controlled with samples of artificial rain reference (ERMCA 408, SigmaAldrich) containing most of the analytes.

Comparison of organic acids measurements in the atmosphere using passive and active sampling

Measurements of organic acids in the atmosphere using diffusion tubes under the conditions of this work are not reported in the literature, and to ensure the efficiency of these types of sampling, two techniques were compared simultaneously, using different reagents: passive sampler using impregnated filters with $0.7 \mathrm{~mol} \mathrm{~L}^{-1}$ triethanolamine $+1.0 \mathrm{~mol} \mathrm{~L}^{-1}$ glycerol and denuder tube coated with $1.0 \times 10^{-2} \mathrm{~mol} \mathrm{~L}^{-1} \mathrm{Na}_{2} \mathrm{CO}_{3}$.

\section{Criteria air pollutants and meteorological parameters}

Data of the average concentrations of criteria air pollutants $\left(\mathrm{CO}\right.$, carbon monoxide; $\mathrm{NO}_{2}$, nitrogen dioxide; $\mathrm{SO}_{2}$, sulfur dioxide; $\mathrm{O}_{3}$, ozone; and $\mathrm{PM}_{10}$, particulate matter $10 \mu \mathrm{m}$ or less in diameter), of NO (nitrogen monoxide) also monitored and the mean values of meteorological parameters in each sampling period were supplied by the Environmental Protection Company (CETREL), responsible for the operation of the air quality monitoring network stations, located next (ca. $2 \mathrm{~m}$ ) to the five sampling sites (Campo Grande, Rio Vermelho, Paralela, Barros Reis and Pirajá) chosen in this study. Met One's multi-parameter sensors were used for wind speed, temperature, relative humidity and precipitation. All criteria air pollutants were determined using automatic analyzers (Environnement SA).

\section{Statistical analysis}

The evaluation of possible correlations between the determined acids concentrations, meteorological parameters and criteria air pollutants concentrations was made using principal component analysis (PCA) and hierarchical cluster analysis (HCA) with the Statistica 7.0 software,$^{20}$ and the linear correlation matrix (Pearson).

\section{Results and Discussion}

Validation of the passive sampler by comparison of the measurements of acids in the atmosphere using passive and active sampling

The validation of the passive samplers for $\mathrm{CH}_{3} \mathrm{COOH}$, $\mathrm{CHOOH}, \mathrm{HCl}$ and $\mathrm{HNO}_{3}$ using impregnated filters with $0.7 \mathrm{~mol} \mathrm{~L}^{-1}$ triethanolamine $+1.0 \mathrm{~mol} \mathrm{~L}^{-1}$ glycerol was performed exposing them simultaneously with a thermodiffusion system using diffusion tubes coated with $1.0 \times 10^{-2} \mathrm{~mol} \mathrm{~L}^{-1} \mathrm{Na}_{2} \mathrm{CO}_{3}$ solution and comparing the results of the average concentrations obtained, considering the active method as reference.

The accuracy of the measurements using the passive sampler, based on the relative error percentage, and the precision expressed as variation coefficient for each set of three passive samplers were determined. The average accuracy (15 to $18 \%$ ) of these measurements were within the recommended limit by the European Union ${ }^{21}( \pm 25 \%)$ for this type of device, and the values of average precision (16 to $19 \%$ ) were less than the $20 \%$ (Table 1) usually found in the literature. ${ }^{19,22}$ Statistical analysis of the data was performed using the $F$-test to quantify the accuracy of the methods and the paired $t$-test to evaluate differences between the averages. The results showed no significant difference between the average concentrations obtained by the two methods (Table 1).

Concentrations of organic and inorganic acids in the city of Salvador

The results of the measurements of acids in the gas phase in five sites of the city of Salvador with passive samplers for periods of two weeks in rainy and dry seasons are presented in Figures 2a and 2b, respectively. During the dry period, the concentrations ranges obtained were: $0.48-8.64 \mu \mathrm{g} \mathrm{m}^{-3}$ for $\mathrm{CH}_{3} \mathrm{COOH}, 0.90-5.92 \mu \mathrm{g} \mathrm{m}^{-3}$ for $\mathrm{HCOOH}, 0.42-0.95 \mu \mathrm{g} \mathrm{m}^{-3}$ for $\mathrm{HCl}, 0.10-0.87 \mathrm{~g} \mathrm{~m}^{-3}$ for $\mathrm{HNO}_{3}$. In the rainy period, the concentrations ranges found were: $2.70-8.17 \mu \mathrm{g} \mathrm{m}^{-3}$ for $\mathrm{CH}_{3} \mathrm{COOH}$, 2.52-6.20 $\mu \mathrm{g} \mathrm{m}^{-3}$ for $\mathrm{HCOOH}, 0.45-0.85 \mu \mathrm{g} \mathrm{m}^{-3}$ for $\mathrm{HCl}$ and $0.13-0.27 \mu \mathrm{g} \mathrm{m}^{-3}$ for $\mathrm{HNO}_{3}$. The $\mathrm{H}_{2} \mathrm{SO}_{4}$, which is incorporated to the atmospheric particulate matter, was measured with the thermodiffusion system only in the rainy season, due to problems related to the equipment operation, and it presented the concentration range between 0.20 and $0.30 \mu \mathrm{g} \mathrm{m}^{-3}$. 
Table 1. Evaluation of the passive sampler for acetic, formic, hydrochloric and nitric acids by comparison with measurements of these acids in the atmosphere using active sampling

\begin{tabular}{|c|c|c|c|c|c|c|c|c|}
\hline \multirow{2}{*}{ Variable } & \multicolumn{2}{|c|}{$\mathrm{CH}_{3} \mathrm{COOH}$} & \multicolumn{2}{|c|}{$\mathrm{CHOOH}$} & \multicolumn{2}{|c|}{$\mathrm{HCl}$} & \multicolumn{2}{|c|}{$\mathrm{HNO}_{3}$} \\
\hline & PS & TS & PS & TS & PS & TS & PS & TS \\
\hline Average concentration / $\left(\mu \mathrm{g} \mathrm{m}^{-3}\right)$ & 4.8 & 4.3 & 4.4 & 3.9 & 0.7 & 0.6 & 0.20 & 0.19 \\
\hline Variance $\left(\mathrm{S}^{2}\right)$ & 5.2 & 4.7 & 2.8 & 2.7 & $3.0 \times 10^{-2}$ & $4.4 \times 10^{-2}$ & $3.0 \times 10^{-3}$ & $1.0 \times 10^{-3}$ \\
\hline Variation coefficient / \% & 15.7 & - & 16.6 & - & 19.4 & - & 16.9 & - \\
\hline Relative error / \% & 17.9 & & 14.8 & & 15.9 & & 15.0 & \\
\hline$F$ & 1.12 & & 1.03 & & 1.50 & & 2.50 & \\
\hline$F_{\text {critical }}$ & 5.05 & & 5.05 & & 5.05 & & 5.05 & \\
\hline$t$ & 0.30 & & 0.50 & & 0.10 & & 0.48 & \\
\hline$t_{\text {critical }}$ & 2.31 & & 2.31 & & 2.31 & & 2.31 & \\
\hline
\end{tabular}

PS: passive sampler; TS: thermodiffusion system.

(a)

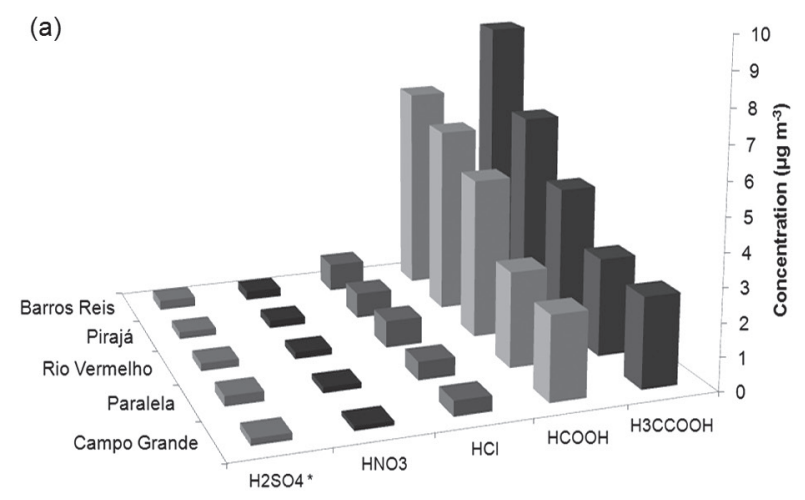

(b)

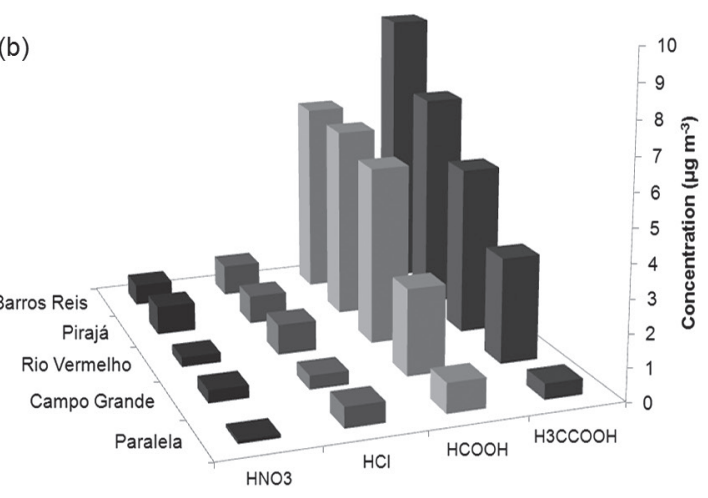

Figure 2. Average concentrations of organic and inorganic acids in the city of Salvador, in (a) rainy (*average concentrations obtained by thermodiffusion system) and (b) dry seasons.

Figure 2 shows that in all sampling sites, the organic acids (acetic and formic) presented the highest concentration levels when compared with inorganic acids, demonstrating the importance of these acids in the atmosphere of this city. In addition, the concentrations of acetic acid are higher than that of formic acid, confirming the contribution of the emission from the diesel with biodiesel, hydrated ethanol and gasohol fueled vehicles, agreeing with other works carried out in Brazil. ${ }^{8,12,23}$ Considering the five acids measured in this study, it was estimated that the two organic acids contributed, on average, to $89 \%$ of the acidity of the city's atmosphere (acetic acid with $48 \%$ and formic acid $41 \%$ ). The inorganic acids contributed, on average, as follows: hydrochloric acid, $6.5 \%$; sulfuric acid, $2.6 \%$ and nitric acid, $1.9 \%$.

The Brazilian environmental legislation, ${ }^{24}$ that deals with the ambient air pollution, does not define standards for acids compounds as many other countries do. Thus, in this study, the acids concentrations found in the city of Salvador were compared with the limits established by the Ontario Ministry of the Environment ${ }^{25}$ and it was verified that the concentration levels found are far below these limits (at least 20 times smaller).

The highest organic acids concentrations were found in the Barros Reis sampling site, an important flow corridor of the city's road system with intense flow of heavy vehicles using diesel with addition of biodiesel. This avenue is an access road to several neighborhoods of the city of Salvador and an exit to one of the main federal highways in the state of Bahia (BR-324). Another aspect that corroborates the concentrations found in this site is its topography; it is a valley, which concentrates the emissions and hinders the dispersion of atmospheric pollutants. Similar organic acids concentrations were found in Pirajá, which also has intense heavy vehicles traffic since it is situated close to BR-324, and it hosts an important bus station (Pirajá transhipment station).

Rio Vermelho, which receives intense traffic of public transportation (buses) as it links two important avenues of the city, is a region that is influenced by sea salt emissions, which accounts for the higher concentrations of hydrochloric acid compared to other sampling sites, 
probably due to the formation through reactions of precursors or other inorganic acids with the $\mathrm{NaCl}$ of the marine spray.

In the Paralela site, it was observed, in general, that the measured acids concentrations were lower when compared to most sites, even though this avenue has the highest flow of light vehicles using mainly gasohol and hydrated ethanol compared with the other avenues of the city of Salvador. The justification for this fact can be related to the extensive coverage of Atlantic Forest present along this avenue, which probably captures gaseous pollutants. ${ }^{26}$ In addition, the topography of the site favors atmospheric dispersion, since it is a flat area with constant ventilation. In the Campo Grande site, low acids concentrations were also found, which is likely to be related to the lower vehicular traffic when compared to other areas where this study was carried out.

\section{Influence of meteorological parameters}

Salvador is a city with a tropical climate and it presents two well defined precipitation periods: rainy (April to August) and dry (September to March). However, seasonal variations of temperatures are not very expressive, with an average of ca. 24 and $27{ }^{\circ} \mathrm{C}$ in the rainy and dry periods, respectively. Figure S2 (SI section) shows the meteorological characteristics of the sites of this study: wind roses constructed using WRPLOT View software, ${ }^{27}$ average temperatures and precipitation for each sampling site in the two sampling periods.

The concentrations of the acids measured in this study showed a small variation in the two periods in most of the sampled sites except for Paralela (site A), which presented a considerable decrease in the concentrations of these acids in the dry period. This can be justified by observing Figure S2 (SI section), which shows a great similarity between the system of winds at the sampling sites for the two periods (predominantly southeastern), only varying the intensity of the winds, except for that referring to the Paralela site in the dry period, which receives masses of air practically coming from the ocean.

Comparison between levels of acids in the urban atmosphere of Salvador and other sites

Comparing the concentrations of the acids found in this study with those obtained in urban areas of other brazilian cities ${ }^{10,11,13,14,28}$ and in other parts of the world ${ }^{22,29,30}$ (Table 2), it is possible to observe that the concentrations are in the same order of magnitude and the variations between the results can be attributed to the differences in the composition of the fuels used, traffic intensity in the different regions, as well as the influence of seasonal local and/or meteorological factors.

\section{Characterization of emission sources}

The results found for the ratios of the formic and acetic acids concentrations (F/A) are presented in Table 3 and they were used to suggest the origin of these acids in the atmosphere of the city of Salvador.

Ratios greater than 1 show the predominance in the formation of organic acids in situ by photochemical reactions. Ratios lower than 1 are indicative of direct emissions of these compounds, which is typical of Brazilian cities where the use of oxygenated fuels, especially hydrated ethanol and gasohol, is intense. ${ }^{10-12}$

Table 2. Organic and inorganic acids concentrations reported in urban atmosphere of other localities compared to this study

\begin{tabular}{|c|c|c|c|c|c|c|}
\hline \multirow{2}{*}{ Site } & \multicolumn{5}{|c|}{ Acid concentration / $\left(\mu \mathrm{g} \mathrm{m}^{-3}\right)$} & \multirow{2}{*}{ Reference } \\
\hline & $\mathrm{HCOOH}$ & $\mathrm{H}_{3} \mathrm{CCOOH}$ & $\mathrm{HCl}$ & $\mathrm{HNO}_{3}$ & $\mathrm{H}_{2} \mathrm{SO}_{4}$ & \\
\hline Salvador (Brazil) & $0.90-6.2$ & $0.48-8.6$ & $0.42-0.95$ & $0.10-0.87$ & $0.20-0.30$ & this study \\
\hline São Paulo (Brazil) & $1.1-36$ & $0.20-26$ & ND & ND & ND & 10 \\
\hline São Paulo (Brazil) & $1.1-18$ & $1.2-20$ & ND & ND & ND & 11 \\
\hline Camaçari (Brazil) & ND & ND & $0.4-0.56$ & $0.010-0.20$ & $0.10-1.70$ & 13 \\
\hline Madre Deus (Brazil) & ND & ND & $0.30-0.60$ & $0.010-0.18$ & $0.10-1.3$ & 13 \\
\hline Candeias (Brazil) & ND & ND & $0.60-0.70$ & $0.12-0.20$ & $0.090-0.10$ & 14 \\
\hline Dias D’Ávila (Brazil) & ND & ND & $0.30-3.9$ & $0.040-0.64$ & $0.020-0.12$ & 14 \\
\hline Southern Region (Vietnam) & $5.4-16$ & $5.5-21$ & $0.15-0.21$ & $0.67-3.2$ & ND & 22 \\
\hline Araraquara (Brazil) & $2.3-36$ & $0.20-13$ & $0.10-1.9$ & $0.10-5.4$ & ND & 28 \\
\hline Copenhagen (Denmark) & $0.56-2.8$ & $0.98-6.9$ & ND & ND & ND & 29 \\
\hline Brussels (Belgium) & $1.7-16$ & $3.2-20$ & ND & ND & ND & 29 \\
\hline Philadelphia (USA) & $0.5-43$ & $0.7-28$ & ND & ND & ND & 30 \\
\hline
\end{tabular}

ND: not determined. 
Table 3. Ratios between the formic and acetic acids concentrations (F/A) in rainy and dry periods in the city of Salvador

\begin{tabular}{lcc}
\hline \multirow{2}{*}{ Sampling site } & \multicolumn{2}{c}{ F/A } \\
\cline { 2 - 3 } Campo Grande & Rainy period & Dry period \\
Paralela & 0.93 & 0.82 \\
Rio Vermelho & 0.97 & 1.9 \\
Pirajá & 1.1 & 1.0 \\
Barros Reis & 0.97 & 0.88 \\
\hline
\end{tabular}

F/A $<1$ : direct emission of carboxylic acids; F/A $>1$ : in situ formation of photochemical processes.

The data shown in Table 3 suggest that organic acids were emitted directly to the atmosphere in most studied sites in the city of Salvador, except for Paralela in the dry season and Rio Vermelho in both periods, where the formation by photochemical processes seems to be more favored. Similar reasons were found in São Paulo with values in the range of 0.9-1.8. ${ }^{11,12}$ For Salvador, as well as other urban centers in the country, these emissions are directly related to the vehicle fleet that has grown considerably over the years.

Comparing the F/A ratios found in this study with the ratios between formaldehyde and acetaldehyde concentrations (FA/AA), which are precursors of these organic acids, found in a previous study ${ }^{16}$ carried out at about the same time and also in the city of Salvador, it was verified that in sites with significant influence of public transport (buses), such as Rio Vermelho and Campo Grande, and heavy vehicles, such as Barros Reis and Pirajá, the FA/ AA ratios were predominantly smaller than 1 . The reason for this is that the addition of biodiesel to the diesel in these types of vehicles increases the emissions of acetaldehyde into the atmosphere..$^{8,31,32}$

In addition, when compounds are derived from a common emission source, the average compositions of these compounds is expected to be maintained over time and thus, these compounds should have concentrations that are linearly correlated among them. ${ }^{12,22}$ Figure 3 shows the correlations between the organic acids concentrations studied in both rainy and dry periods. This figure shows that there is a good correlation between the formic and acetic acids concentrations for both periods. This is a indicative that these acids are emitted predominantly from the same emission source, which in the case of Salvador should predominantly be from the vehicular fleet.

\section{Multivariate analysis}

PCA and HCA were applied to the data matrices obtained in the five sampling sites using Statistica

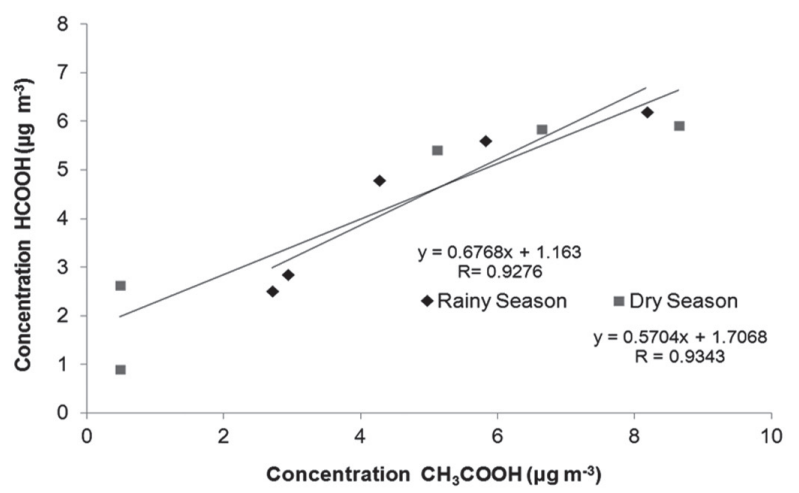

Figure 3. Correlations obtained between the acetic and formic acids concentrations.

software, ${ }^{20}$ aiming to identify correlations between the determined acids concentrations, criteria air pollutants concentrations $\left(\mathrm{PM}_{10}, \mathrm{CO}, \mathrm{NO}_{2}, \mathrm{SO}_{2}\right.$ and $\left.\mathrm{O}_{3}\right)$ and meteorological parameters (temperature, relative humidity, wind speed and precipitation), as well as to determine the relationships between the sites used for the samplings in the city of Salvador. Graphs of loadings and scores involving the first two principal components (Figures 4a and 4b) were constructed for the PCA. The sampling sites were identified as follows: Campo Grande (CGD), Rio Vermelho (RIV), Paralela (PAR), Barros Reis (BAR) and Pirajá (PIR). The indices 1 and 2 were used to define the rainy and dry seasons, respectively.

In Figure $4 a$, it can be seen that, for formic and acetic acids, there is a formation of acute angles between them, which indicates a strong correlation. ${ }^{33}$ This, coupled with their strong correlation with $\mathrm{CO}$, is an indicative that these acids are predominantly emitted by the vehicle fleet, since $\mathrm{CO}$ is used as an indicator for this type of emission in urban areas. $^{34,35}$ It is also possible to verify that in addition to $\mathrm{CO}$, other air pollutants $\left(\mathrm{PM}_{10}, \mathrm{NO}_{2}, \mathrm{NO}\right)$, with the exception of ozone, also presented similarities with these acids, confirming that the organic acids are not produced significantly by photochemical reactions, ${ }^{36}$ but rather emitted directly by the vehicle fleet of the city of Salvador. For sulfuric acid, a strong correlation with the particulate material is observed, since the physical form of this acid in the atmosphere is as fine particles in suspension (aerodynamic diameter $<2 \mu \mathrm{m}$ ) ${ }^{13}$ moreover, the correlation with $\mathrm{SO}_{2}$, which is a precursor in the formation of this acid in the atmosphere, is also verified.

For meteorological parameters such as precipitation, relative humidity and temperature, it is possible to observe negative correlations with most of the pollutants, indicating the influence of these parameters on washing processes to remove pollutants in the atmosphere. ${ }^{37}$

Figure $4 \mathrm{~b}$ shows the similarities of the sampling sites and it helps to elucidate possible trends related to these sites 



Figure 4. (a) Graph of loadings and (b) graph of the scores of PC1 versus PC2 obtained from all variables of this study. WS: wind speed; T: temperature; RH: relative humidity; PPT: precipitation.

or sampling periods through the formation of some groups. Two groups of samples collected in rainy and dry seasons are highlighted: Paralela and Campo Grande, respectively. These groups presented similarity between themselves, with lower concentrations of $\mathrm{CH}_{3} \mathrm{COOH}, \mathrm{HCOOH}, \mathrm{HCl}$ and $\mathrm{HNO}_{3}$. The groups formed by the samples collected in Rio Vermelho and Pirajá in rainy and dry periods had relatively similar concentrations of all acids, as well as similarities in meteorological parameters such as wind speed, temperature and relative humidity. Figure $4 \mathrm{~b}$ also shows that the samples collected in the two periods at the Barros Reis site presented similarity in the positive scores in relation to the first main component. This indicates a strong positive correlation, since the highest organic acids concentrations, as well as high $\mathrm{NO}_{2}, \mathrm{NO}, \mathrm{CO}$ concentrations, were found in this place in both sampling periods, sometimes reaching twice as much the amounts observed in the other sites.

\section{(a)}



As previously stated, the city of Salvador presents a precipitation profile with rainy and dry periods. This profile is clearly confirmed by the formation of two main groups separated by the horizontal axis, where in the upper part the sampling sites are concentrated in the rainy season, and in the lower part in the dry period (Figure 4b).

A very similar behavior of the variables under study can also be verified through the application of the HCA, and its result is presented in a dendrogram form (Figure 5). The grouping of the data was performed using the Ward method, and the metric used to calculate the degree of similarity was 1-Pearson's R distance. ${ }^{33}$

According to the Figure 5a dendrogram, it is possible to confirm that acetic and formic acids present wellestablished linear correlations (high degree of similarity), since they have a small 1-Pearson's distance, signaling that they come from the same emission source. The formation of

(b)

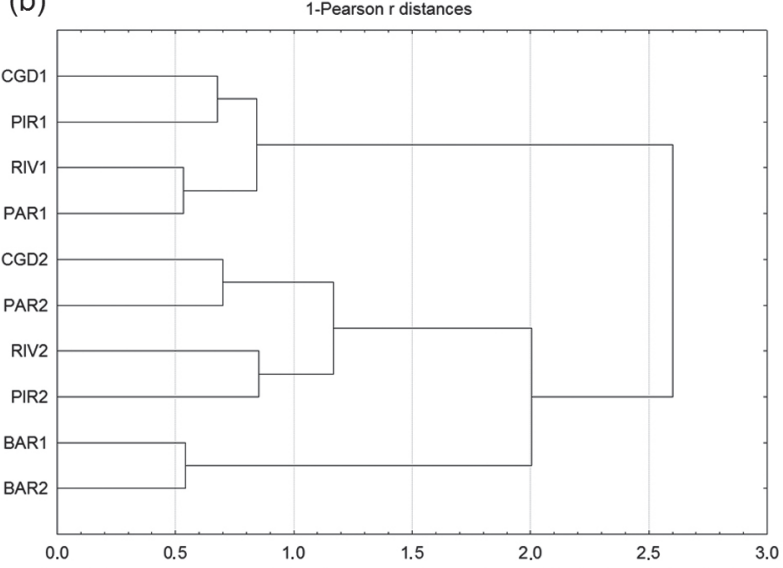

Figure 5. Dendrograms obtained by HCA for: (a) four meteorological parameters, six criteria pollutants and five measured acids; and (b) five sampling sites in rainy and dry periods in Salvador. WS: wind speed; T: temperature; RH: relative humidity; PPT: precipitation. 
a group with sulfuric acid and the particulate material is also observed, confirming the similarities previously suggested.

Figure $5 \mathrm{~b}$ shows the dendrogram that relates the locations where the samplings were performed. This dendogram confirms the formation of the groups discussed previously, showing the groupings of the sites chosen for sampling based on the similarities of the pollutants concentrations, as well as the behavior of the meteorological parameters in the two sampling periods. The similarities presented in this dendrogram reaffirm the discussions made for the graph of the scores obtained for sites sampling (Figure $4 \mathrm{~b}$ ).

Correlation of the studied acids, criteria air pollutants and meteorological parameters

One linear correlation matrix (Pearson) was constructed with the data of the studied acids, criteria air pollutants and meteorological parameters, to confirm previously proposed relationships in the multivariate analysis. The results of the correlation analysis are summarized in Table 4.

The data shown confirm that the organic acids present a very strong correlation with each other, showing that they come from a common source. In addition, both have positive correlations ranging from strong to very strong with pollutants from vehicle emissions such as $\mathrm{CO}, \mathrm{NO}$, $\mathrm{NO}_{2}$ and $\mathrm{SO}_{2}$. It was possible to confirm strong correlations with $\mathrm{PM}_{10}$ and $\mathrm{SO}_{2}$ for $\mathrm{H}_{2} \mathrm{SO}_{4}$, because this acid is in the form of fine particles in the atmosphere, and $\mathrm{SO}_{2}$ is a precursor in its formation. For $\mathrm{HNO}_{3}$, the very strong correlations with $\mathrm{NO}$ and $\mathrm{NO}_{2}$ shows that these compounds, emitted predominantly from the vehicular fleet of the city of Salvador, are precursors in the formation of this acid in the atmosphere. It is also possible to observe that all studied acids have negative correlations with temperature and relative humidity, confirming the influence of these parameters to the removal of acids from the atmosphere.

\section{Conclusions}

This study contributed to elucidate the contribution of organic and inorganic acids to the acidity of the atmosphere of the city of Salvador. Among the organic acids determined in the atmosphere of Salvador, acetic acid was found in higher concentrations in most of the sites measured in both periods, while hydrochloric acid predominated in all sites among the strong inorganic acids. Considering the five acids measured in this study, it was estimated that the two organic acids contributed, on average, to $89 \%$ of the acidity of the city's atmosphere (48\% of acetic acid and $41 \%$ of formic acid), whereas the inorganic acids contributed, on average, with $6.5 \%$ of hydrochloric acid, $2.6 \%$ of sulfuric acid, and $1.9 \%$ of nitric acid. The F/A ratios lower than 1 in most studied sites and the strong correlations between $\mathrm{CO}$ and the organic acids concentrations confirmed that the vehicular emissions in the city of Salvador are, predominantly, the source of these compounds. Pearson's correlation analysis showed that all acids determined in this study were influenced by vehicle emissions. Important correlations were established among the studied acids, meteorological

Table 4. Linear correlation matrix for four meteorological parameters, six criteria air pollutants and five studied acids

\begin{tabular}{|c|c|c|c|c|c|c|c|c|c|c|c|c|c|c|c|c|}
\hline & & 1 & 2 & 3 & 4 & 5 & 6 & 7 & 8 & 9 & 10 & 11 & 12 & 13 & 14 & 15 \\
\hline $\mathrm{CO}$ & 1 & 1.00 & & & & & & & & & & & & & & \\
\hline $\mathrm{O}_{3}$ & 2 & -0.22 & 1.00 & & & & & & & & & & & & & \\
\hline $\mathrm{PM}_{10}$ & 3 & 0.32 & 0.03 & 1.00 & & & & & & & & & & & & \\
\hline $\mathrm{NO}$ & 4 & 0.93 & -0.43 & 0.49 & 1.00 & & & & & & & & & & & \\
\hline $\mathrm{NO}_{2}$ & 5 & 0.87 & -0.05 & -0.07 & 0.64 & 1.00 & & & & & & & & & & \\
\hline WS & 6 & -0.39 & 0.91 & 0.20 & -0.55 & -0.25 & 1.00 & & & & & & & & & \\
\hline $\mathrm{T}$ & 7 & -0.51 & -0.32 & 0.23 & -0.38 & -0.56 & 0.09 & 1.00 & & & & & & & & \\
\hline $\mathrm{RH}$ & 8 & -0.87 & 0.55 & -0.55 & -0.97 & -0.57 & 0.57 & 0.16 & 1.00 & & & & & & & \\
\hline PPT & 9 & 0.73 & -0.37 & -0.16 & 0.74 & 0.63 & -0.70 & -0.76 & -0.61 & 1.00 & & & & & & \\
\hline $\mathrm{SO}_{2}$ & 10 & 0.79 & 0.03 & 0.72 & 0.85 & 0.45 & -0.09 & -0.46 & -0.78 & 0.51 & 1.00 & & & & & \\
\hline $\mathrm{H}_{3} \mathrm{CCOOH}$ & 11 & 0.91 & 0.18 & 0.23 & 0.71 & 0.91 & -0.03 & -0.65 & -0.61 & 0.58 & 0.73 & 1.00 & & & & \\
\hline $\mathrm{HCOOH}$ & 12 & 0.76 & 0.37 & 0.29 & 0.50 & 0.83 & 0.26 & -0.44 & -0.45 & 0.26 & 0.60 & 0.93 & 1.00 & & & \\
\hline $\mathrm{HCl}$ & 13 & 0.68 & 0.37 & 0.54 & 0.49 & 0.66 & 0.37 & -0.22 & -0.47 & 0.05 & 0.65 & 0.83 & 0.95 & 1.00 & & \\
\hline $\mathrm{HNO}_{3}$ & 14 & 0.76 & 0.44 & 0.37 & 0.56 & 0.77 & 0.28 & -0.58 & -0.46 & 0.34 & 0.73 & 0.95 & 0.97 & 0.92 & 1.00 & \\
\hline $\mathrm{H}_{2} \mathrm{SO}_{4}$ & 15 & 0.34 & 0.13 & 0.62 & 0.54 & -0.06 & -0.02 & -0.45 & -0.42 & 0.39 & 0.81 & 0.28 & 0.11 & 0.18 & 0.34 & 1.00 \\
\hline
\end{tabular}

WS: wind speed; T: temperature; RH: relative humidity; PPT: precipitation; in bold: strong $(0.60 \leq|\mathrm{r}|<0.80)$ and very strong correlation $(0.80 \leq|\mathrm{r}|<1.0)$. 
parameters and criteria air pollutants in the atmosphere of this city through PCA and HCA.

\section{Supplementary Information}

Supplementary data are available free of charge at http://jbcs.sbq.org.br as PDF file.

\section{Acknowledgments}

The authors acknowledge the National Council for Scientific and Technological Development (CNPq) and Coordination for the Improvement of Higher Education Personnel (CAPES) of Brazil for fellowships, the Foundation for Research Support of the State of Bahia (FAPESB) for financial support and CETREL for supplying the datas of criteria air pollutants and meteorological parameters from air quality monitoring network in the city of Salvador.

\section{References}

1. Campos, V. P.; Cruz, L. P.; Godoi, R. H.; Godoi, A. F. L.; Tavares, T. M.; Microchem. J. 2010, 96, 132.

2. Finlayson-Pitts, B. J.; Pitts Jr, J. N.; Chemistry of the Upper and Lower Atmosphere - Theory, Experiments, and Applications; Academic Press: San Diego, 2000.

3. Souza, S. R.; Carvalho, L. R. F.; Quim. Nova 2001, 24, 60.

4. Paulot, F.; Wunch, D.; Crounse, J. D.; Toon, G. C.; Millet, D. B.; DeCarlo, P. F.; Vigouroux, C.; Deutscher, N. M.; González Abad, G.; Notholt, J.; Warneke, T.; Hannigan, J. W.; Warneke, C.; de Gouw, J. A.; Dunlea, E. J.; De Mazière, M.; Griffith, D. W. T.; Bernath, P.; Jimenez, J. L.; Wennberg, P. O.; Atmos. Chem. Phys. 2011, 11, 1989.

5. Atkinson, R.; Atmos. Environ. 2000, 34, 2063.

6. Yao, X. H.; Fang, M.; Chan, C. K.; Environ. Sci. Technol. 2001, 35,600 .

7. Conselho Nacional do Meio Ambiente (CONAMA); Resolução CONAMA No. 18, de 6 de maio de 1986, Dispõe sobre a Criação do Programa de Controle de Poluição do Ar por Veículos Automotores - PROCONVE; Diário Oficial da União, Brasília, seção 1, p.8792-8795. Available at http://www2. $\mathrm{mma}$. gov.br/port/conama/legiabre.cfm?codlegi=41, accessed in November 2018.

8. Rodrigues, M. C.; Guarieiro, L. L. N.; Cardoso, M. P.; Carvalho, L. S.; da Rocha, G. O.; de Andrade, J. B.; Fuel 2012, 92, 258.

9. Nogueira, T.; Dominutti, P. A.; Carvalho, L. R. F.; Fornaro, A.; Andrade, M. F.; Fuel 2014, 134, 505.

10. Montero, L.; Vasconcellos, P. C.; Souza, S. R.; Pires, M. A. F.; Sanchez-Ccoyllo, O. R.; Andrade, M. F.; Carvalho, L. R. F.; Environ. Sci. Technol. 2001, 35, 3071.
11. Souza, S. R.; Vasconcellos, P. C.; Carvalho, L. R. F.; Atmos. Environ. 1999, 33, 2563.

12. Souza, S. R.; Carvalho, L. R. F.; J. Braz. Chem. Soc. 2001, 12, 755.

13. Campos, V. P.; Couto, E. R.; Miranda, J. P.; Almeida, A. S.; Cruz, L. P.; Barbosa, J. L.; Tavares, T. M.; Microchem. J. 2013, 109, 58 .

14. Campos, V. P.; Tavares, T. M.; Cruz, L. P. S.; Miranda, J. P.; Costa, T. A. C.; Barbosa, J. L. In Atlas Socioambiental do Recôncavo Baiano, $1^{\mathrm{a}}$ ed.; Tavares, T. M.; Nascimento, D. M. C., eds.; UFBA: Salvador, 2014, p. 139.

15. Marć, M.; Tobiszewski, M.; Zabiegała, B.; de la Guardia, M.; Namieśnik, J.; Anal. Chim. Acta 2015, 853, 116.

16. Santana, F. O.; Campos, V. P.; Cruz, L. P. S.; Luz, S. R.; Microchem. J. 2017, 134, 78.

17. http://www.denatran.gov.br/index.php/estatistica/610frota-2017, accessed in November 2018.

18. Cruz, L. P.; Campos, V. P.; Novaes, J. A.; Tavares, T. M.; J. Braz. Chem. Soc. 2005, 16, 50.

19. Cruz, L. P.; Campos, V. P.; Silva, A. M. C.; Tavares, T. M.; Atmos. Environ. 2004, 38, 6425.

20. Statistica Software 7.0; StatSoft, Tulsa, OK, USA, 2004.

21. European Commission; Directive 2008/50/EC of the European Parliament and of the Council of 21 May 2008, on Ambient Air Quality and Cleaner Air for Europe; Official Journal of the European Union, 2008, L152. Available at https://eur-lex.europa.eu/LexUriServ/LexUriServ.do?uri=OJ: L:2008:152:0001:0044:en:PDF, accessed in April 2018.

22. Lan, T. T. N.; Nishimura, R.; Tsujino, Y.; Imamura, K.; Warashina, M.; Hoang, N. T.; Maeda, Y.; Anal. Sci. 2004, 20, 213.

23. Vasconcellos, P. C.; Carvalho, L. R. F.; Pool, C. S.; J. Braz. Chem. Soc. 2005, 16, 1210.

24. Conselho Nacional do Meio Ambiente (CONAMA); Resolução No. 003 de 28 de junho de 1990, Dispõe sobre Padrões de Qualidade do Ar, Previstos no PRONAR; Diário Oficial da União, Brasília, 1990, seção 1, p. 15937. Available at http:// www.mma.gov.br/port/conama/legiabre.cfm?codlegi=100, accessed in May 2018.

25. Standards Development Branch, Ontario Ministry of the Environment; Ontario's Ambient Air Quality Criteria; Ontario Ministry of the Environment, 2012. Available at http://www. airqualityontario.com/downloads/AmbientAirQualityCriteria. pdf, accessed in May 2018.

26. Godoi, A. F. L.; Godoi, R. H. M.; Azevedo, R.; Maranho, L. T.; Quim. Nova 2010, 33, 827.

27. WRPLOT View, version 7.0, Lakes Environmental, Waterloo, ON, Canada, 2011.

28. da Rocha, G. O.; Franco, A.; Allen, A. G.; Cardoso, A. A.; J. Geophys. Res.: Atmos. 2003, 108, 4207.

29. Granby, K.; Christensen, C. S.; Lohse, C.; Atmos. Environ. 1997, 31, 1403. 
30. Lawrence, J.; Koutrakis, P.; Anal. J. Geophys. Res. 1996, 101, 9171.

31. Correa, S.; Arbilla, G.; Atmos. Environ. 2008, 42, 769.

32. Guarieiro, L. L.; Pereira, P. A. P.; Torres, E. A.; da Rocha, G. O.; de Andrade, J. B.; Atmos. Environ. 2008, 42, 8211.

33. Correia, P. R. M.; Ferreira, M. M. C.; Quim. Nova 2007, 30, 481.

34. Yuan, B.; Veres, P. R.; Warneke, C.; Roberts, J. M.; Gilman, J. B.; Koss, A.; Edwards, P. M.; Graus, M.; Kuster, W. C.; Li, S.-M.; Wild, R. J.; Brown, S. S.; Dubé, W. P.; Lerner, B. M.; Williams, E. J.; Johnson, J. E.; Quinn, P. K.; Bates, T. S.; Lefer, B.; Hayes, P. L.; Jimenez, J. L.; Weber, R. J.; Zamora,
R.; Ervens, B.; Millet, D. B.; Rappenglück, B.; de Gouw, J. A.; Atmos. Chem. Phys. 2015, 15, 1975.

35. Morknoy, D.; Khummongkol, P.; Prueaksasit, T.; Water, Air, Soil Pollut. 2011, 216, 693.

36. Seinfeld, J. H.; Pandis, S. N.; Atmospheric Chemistry and Physics: from Air Pollution to Climate Change; John Wiley \& Sons: Hoboken, 2016.

37. Zhang, H.; Wang, Y.; Hu, J.; Ying, Q.; Hu, X.-M.; Environ. Res. 2015, 140, 242.
Submitted: September 18, 2018

Published online: November 22, 2018 